\title{
Article \\ A Wireless Power Transfer Charger with Hybrid Compensation Topology for Constant Current/Voltage Onboard Charging
}

\author{
Guangyao Li (1) and Dong-Hee Kim *(1) \\ Department of Electrical Engineering, Chonnam National University, 77 Yongbong-ro, Buk-gu, \\ Gwangju 61186, Korea; lgywjm@hotmail.com \\ * Correspondence: kimdonghee@jnu.ac.kr; Tel.: +82-62-530-1736
}

check for updates

Citation: Li, G.; Kim, D.-H. A Wireless Power Transfer Charger with Hybrid Compensation Topology for Constant Current/Voltage Onboard Charging. Appl. Sci. 2021, 11, 7569. https://doi.org/10.3390/app11167569

Academic Editors: Bor-Ren Lin and Chien-Ming Wang

Received: 22 July 2021

Accepted: 16 August 2021

Published: 18 August 2021

Publisher's Note: MDPI stays neutra with regard to jurisdictional claims in published maps and institutional affiliations.

Copyright: (c) 2021 by the authors. Licensee MDPI, Basel, Switzerland. This article is an open access article distributed under the terms and conditions of the Creative Commons Attribution (CC BY) license (https:/ / creativecommons.org/licenses/by/ $4.0 /)$.

\begin{abstract}
Compared with plugged-in chargers, wireless power transfer (WPT) systems for battery chargers have numerous advantages, e.g., safety, efficiency, and convenience. To satisfy the important wireless charging requirements of efficiency and safety of the battery, this paper proposes a constant current/voltage $(\mathrm{CC} / \mathrm{CV})$ charging compensation topology with near-communication based on receiving-side hybrid topology switching, which is unaffected by the dynamic loads. The proposed hybrid topology is systematically analyzed by using the M-mode, and the system parameters are designed to satisfy the constraints of zero phase angle (ZPA) and the specified CC output. In the $\mathrm{CV}$ mode, one shunt capacitor is employed to the compensation topology for the CV output and ZPA realization. Both the CC and CV modes are operated under the conditions of zero voltage switching (ZVS) for reducing the loss of the WPT systems. The proposed hybrid compensation topology is controlled by the receiving side and does not require real-time communication to avoid sophisticated control logic. Finally, a 1.1-kW experimental prototype charger based on DS-LCC and LCC-S topologies was established to verify the charging performance of the proposed WPT systems. The maximum efficiency of the proposed WPT charger was found to be approximately $91 \%$. The experimental results were consistent with those of the theoretical analysis.
\end{abstract}

Keywords: wireless power transfer; hybrid compensation topology; constant current/voltage charging; zero phase angle; battery charging

\section{Introduction}

Wireless power transfer (WPT) technology can transfer electrical energy from a highfrequency power supply to a load through a magnetic field instead of a wire connection [1]. It has considerable development potential given its unique advantages, such as safety, efficiency, convenience, and weatherproof-ness, which make it desirable for application in daily life, similar to WiFi. Owing to such advantages, WPT charging can be used in several fields, such as non-removable medical implants [2,3], underwater equipment [4], portable electronic devices [5,6], and other industrial fields. In particular, applications in the field of electric vehicles have attracted widespread attention [7] because of the environmental friendliness, high efficiency, and high success ratio of vehicle-to-grid interaction. However, most electric vehicles adopt conventional plugged-in chargers, which are unsafe, inconvenient, and space-occupying. The emergence of WPT technology is regarded as a preferred solution to the problems of traditional charging methods, boosting the development of the electric vehicle industry.

In general, most of the energy storage devices use lithium batteries, owing to their inherent advantages of high energy, light weight, and strong power tolerance. However, the equivalent resistance of the battery varies with respect to the charging voltage or current. To obtain the expected charging voltage or current for different modes under a dynamic load, the battery charging was mainly accomplished in two stages: an initial constant current $(\mathrm{CC})$ charging stage and then a constant voltage (CV) charging stage, as shown 
in Figure 1. First, the battery was charged at a constant charging current $I_{\mathrm{BAT}}$, but the battery voltage continued to increase with the increasement of the resistance. To avoid the damage of the battery caused by overcharging, while the output voltage of the charger rose to the preset voltage $U_{\mathrm{BAT}}$, the charger needed to quickly switch to $\mathrm{CV}$ mode. Finally, the charging was completed when the charging current was reduced to near zero. However, the drastic change of battery resistance brought great challenges to the design of WPT charging systems.

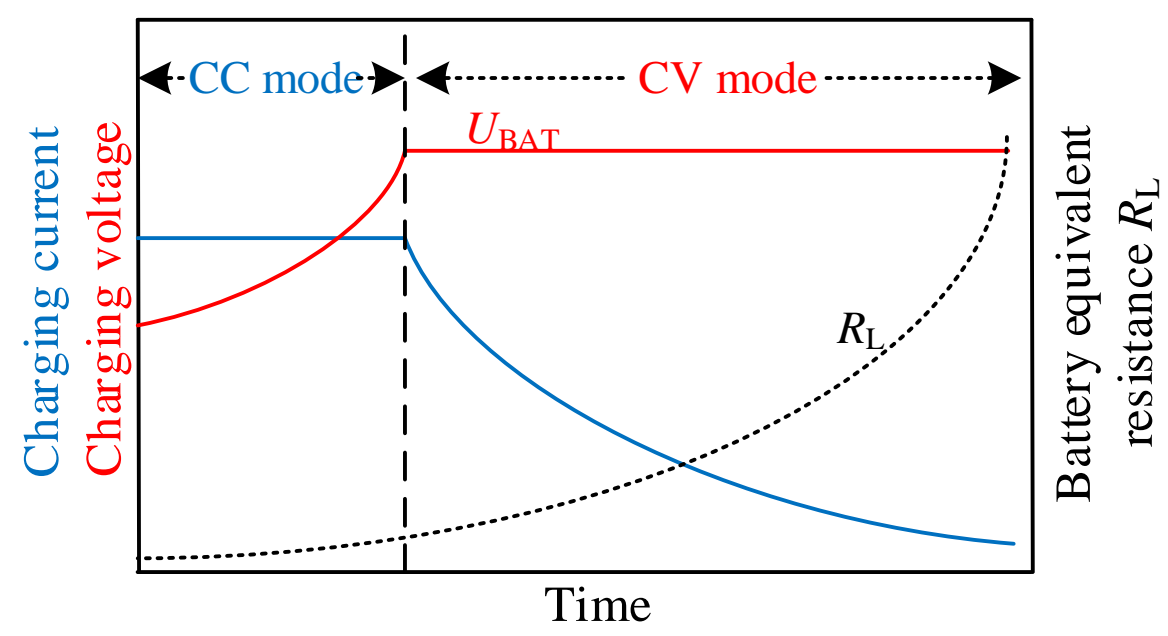

Figure 1. Typical charging profile of the battery.

To achieve a high-efficiency CC/CV output under dynamic loads, researchers have proposed many schemes for WPT charging systems. These schemes can be roughly divided into three categories.

Category 1: Wu et al. [8] proposed a new two-way control scheme for optimizing the charging efficiency of the system, which involves the addition of a DC/DC converter on the primary or secondary side. Ahn et al. [9] proposed an automatic feedback control method with a fast response and simple hardware, which can perform impedance matching and obtain the CC/CV output by adjusting the duty cycle. Li et al. [10] proposed a maximum efficiency point-tracking control scheme to maximize the system efficiency while adjusting the output voltage. However, the additional DC/DC converter increases the cost of the WPT charging systems and reduces the transmission efficiency.

Category 2: Vu et al. [11] proposed a design for WPT systems, which can achieve $\mathrm{CC} / \mathrm{CV}$ charging modes by adopting the load-independent characteristics under zero phase angle (ZPA) conditions with minimal frequency changes throughout the charging process. Yang et al. [12] proposed a novel inductor-capacitor-capacitor-capacitor series (LCCC-S) compensation topology and a parameter correction scheme for obtaining the $\mathrm{CC} / \mathrm{CV}$ modes at two different ZPA working frequency points. Byeon et al. [13] proposed a hybrid control method for a limited operating frequency range, which by using frequency modulation control to realize zero-voltage switching (ZVS) operation and phase-switching control to adjust the output voltage. However, a wide range of pulse-width modulation is usually desired, which increases the switch losses and volt-ampere (VA) ratings. Additionally, the foregoing control methods is not only complicated, but also should maintain real-time communication between the primary and secondary sides.

In addition to the aforementioned complex control strategies that can provide a $\mathrm{CC}$ or $\mathrm{CV}$ output, researchers have considered using a switching hybrid topology to achieve a CC/CV output under dynamic loads without the need for complex control strategies [14]. There are four main types of compensation topologies studied, which have certain required characteristics at a specified resonant frequency [15]. For example, under the precondition of satisfying the ZPA, series-series (S-S) and parallel-parallel (P-P) compensation topologies can achieve a CC output under dynamic loads, while series- 
parallel (S-P) and parallel-series (P-S) topologies can achieve a CV output $[7,16]$. However, research on charging the battery in two modes simultaneously is lacking. Additionally, Auvigne et al. [17] realized a charger with $\mathrm{CC} / \mathrm{CV}$ output by using the combination between S-S and S-P topologies with different compensation parameters; however, the circuit was complex and contained a center loose circuit of taps. S-P compensation topologies were comprehensively analyzed by $\mathrm{Qu}$ et al. [18], and two types of load-independent output currents and voltages were realized by switching between S-S and P-S topologies. However, the hybrid topology requires not only three switches and an additional inductor, but also a wireless real-time communication link.

The CC or CV output of low-order WPT systems under dynamic loads are limited by the loosely coupled transformer (LCT) parameters, which reduces the system design freedom. In many WPT applications, the size or position of the LCT is limited within a certain range, and the available LCT parameters do not meet the requirements of the CC/CV charging mode. To obtain more freedom of the WPT system design, many high-order compensation topologies with multiple compensation components are proposed [19-24]. For instance, the double side-LCC (DS-LCC) compensation topology with a compensated inductor and two compensated capacitors on each side of the LCT [20-22] is used to achieve a CC output under dynamic loads. The LCC-S compensation topology has the advantage that there is no ZPA frequency fluctuation according to the load, and the current flowing to the transmitting coil can be constantly supplied regardless of the dynamic loads and coupling-coefficient fluctuations [25-28]. Additionally, both DS-LCC and LCC-S topologies can meet the requirements of low reactive power and soft switching at the same time, and the greater freedom of system design undoubtedly promotes the design of WPT converters. However, there are few ideas for implementing CC/CV charging by using a hybrid high-order compensation topology with near-communication on the secondary side.

On the basis of the foregoing studies, this paper proposes a secondary side nearcommunication switching hybrid compensation topology method for the battery charging. Two AC switches (ACSs) and one auxiliary capacitor are employed on the secondary side to realize $\mathrm{CC} / \mathrm{CV}$ charging mode under dynamic loads. The advantages of the proposed WPT charging systems are as follows: (1) There is no need for real-time communication between the primary and secondary sides, which eliminates wireless communication equipment, reduces the cost, and improves the reliability of charging. (2) The proposed WPT charging systems can achieve a lower VA ratio under condition of ZVS at a fixed working frequency of $85 \mathrm{kHz}$, which effectively enhanced the system effectiveness. A 1.1-kW prototype is used to verify the proposed WPT systems. The experimental results showed that the maximum system efficiency of CC and CV charging stages were approximately $90.9 \%$ and $91 \%$, respectively.

The structure of this paper is organized as follows: A systematic theoretical analysis of the DS-LCC and LCC-S topologies is described in Section 2. Section 3 proposes that a hybrid compensation topology can realize CC/CV output under dynamic loads with ZPA conditions, and the method of parameter correction. Section 4 establishes the experimental device and verifies the feasibility of the theoretical analysis. The conclusions of the study are described in Section 5.

\section{Theoretical Analysis}

\subsection{Implementation of CC Mode with ZPA Condition}

To achieve a load-independent $C C$ output characteristic with high design freedom of the transfer gain, the DS-LCC compensation topology is proposed. Its design adopted the symmetric tuning scheme with the same compensation network parameters for the primary and secondary sides. The schematic diagram of the DS-LCC compensation wireless charging system is shown in Figure 2. 


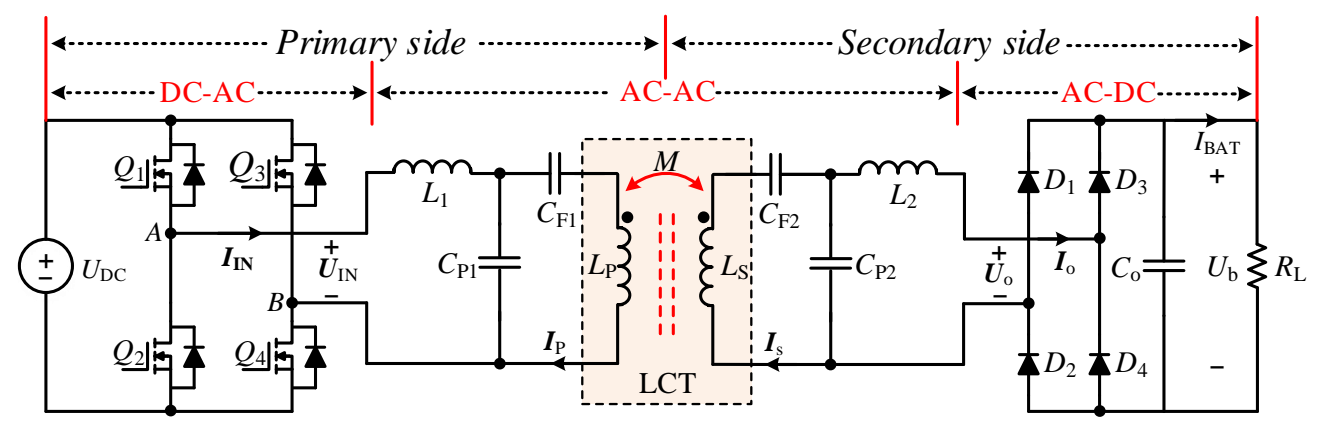

Figure 2. DS-LCC compensated WPT charging systems.

On the primary side, the DC source $U_{\mathrm{DC}}$ was converted to a square wave voltage $U_{\mathrm{IN}}$ through the full bridge inverter (FBI) and then flowed into the DS-LCC resonance compensation topology. $L_{1}, C_{\mathrm{P} 1}$, and $C_{\mathrm{F} 1}$ represent the primary side compensated inductor and capacitors. $L_{2}, C_{\mathrm{P} 2}$, and $C_{\mathrm{F} 2}$ are the secondary side compensation components. $C_{\mathrm{F} 1}$ and $C_{\mathrm{F} 2}$ are the DC blocking capacitors used to eliminate the DC current component. $M$ is the mutual inductance between the two sides. $Q_{1}-Q_{4}$ represent $\mathrm{SiC}$ metal-oxide semiconductor field-effect transistors (MOSFETs) of the FBI, while $D_{1}-D_{4}$ represent diodes of the rectifier. $U_{\mathrm{O}}$ and $I_{\mathrm{O}}$ represent the output voltage and current of the DS-LCC topology, respectively.

The $M$-type and $T$-type models are widely used to analyze WPT charging systems. When the self-inductance and the compensation capacitor should interact in the compensation network, the $M$-type model has more advantages than the T-type model [29]. Therefore, the $M$-type model is adapted to investigate the DS-LCC compensation topology, as shown in Figure 3.

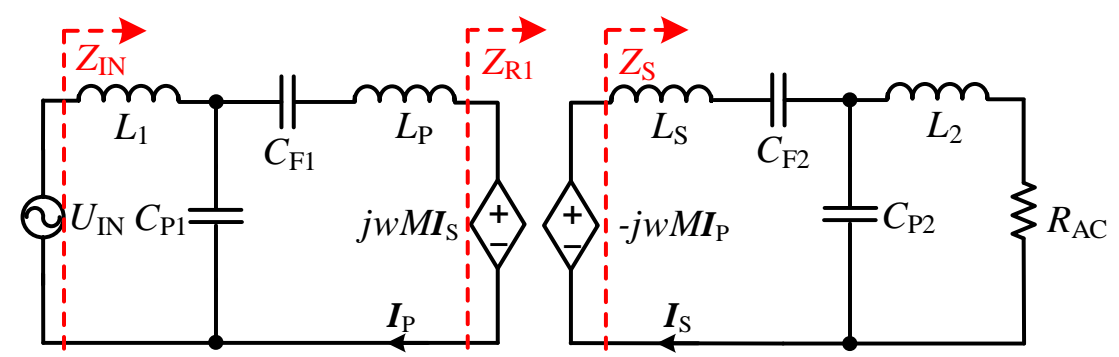

Figure 3. Equivalent $M$-type model of the DS-LCC topology for the CC charging.

To facilitate the analysis, the equivalent $M$-type model in Figure 3 can be converted into the model shown in Figure 4.

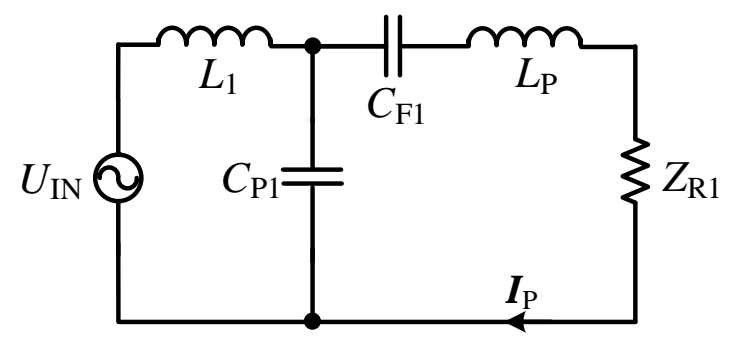

Figure 4. Primary side circuit diagram of the DS-LCC topology with reflected impedance.

According to the Kirchhoff's voltage law $(\mathrm{KCL})$, the equivalent impedance $Z_{\mathrm{S}}$ and the reflection impedance $Z_{\mathrm{R} 1}$ of the secondary side can be deduced as (1):

$$
\left\{\begin{array}{l}
Z_{\mathrm{S}}=j \omega L_{\mathrm{S}}+\frac{1}{j \omega C_{\mathrm{F} 2}}+\frac{1}{j \omega C_{\mathrm{P} 2}} \|\left(j \omega L_{2}+R_{\mathrm{AC}}\right) \\
Z_{\mathrm{R} 1}=\frac{\omega^{2} M^{2}}{Z_{\mathrm{S}}} .
\end{array}\right.
$$


where the symbol "||" expresses the parallel connection.

The input equivalent impedance $Z_{\mathrm{IN}}$ and the input phase angle $Q_{\mathrm{IN}}$ of the simplified $M$-type model of the DS-LCC topology can be expressed as follows:

$$
\left\{\begin{array}{l}
Z_{\mathrm{IN}}=j \omega L_{1}+\frac{1}{j \omega C_{\mathrm{P} 1}} \|\left(j \omega L_{\mathrm{P}}+\frac{1}{j \omega C_{\mathrm{F} 1}}+Z_{\mathrm{R} 1}\right) \\
Q_{\mathrm{IN}}=\frac{180^{\circ}}{\pi} \arctan \frac{I_{\mathrm{m}}\left(Z_{\mathrm{IN}}\right)}{R_{\mathrm{e}}\left(Z_{\mathrm{IN}}\right)} .
\end{array}\right.
$$

To obtain the ZPA for achieving CC-output operation, the input equivalent impedance $Z_{\text {IN }}$ can be represented by Equation (3) for eliminating the imaginary part.

$$
Z_{\mathrm{IN}}=j \omega L_{1}+\frac{1}{j \omega C_{\mathrm{P} 1}}+\frac{1}{\omega^{2} C_{\mathrm{P} 1}^{2}\left(Z_{P}+Z_{\mathrm{R} 1}\right)}
$$

where the $Z_{\mathrm{P}}=j \omega L_{\mathrm{P}}+\frac{1}{j \omega C_{\mathrm{F} 1}}+\frac{1}{j \omega C_{\mathrm{P} 1}}$, and $Z_{\mathrm{IN}}$ should satisfy the limited condition as follows:

$$
\left\{\begin{array}{l}
C_{\mathrm{P} 1}\left(\omega^{2} L_{\mathrm{P}} C_{\mathrm{F} 1}-1\right)-C_{\mathrm{F} 1}=0 \\
\omega^{2} L_{1} C_{\mathrm{P} 1}-1=0
\end{array}\right.
$$

$Z_{\mathrm{IN}}$ of the DS-LCC compensation topology can be rewritten as follows:

$$
Z_{\mathrm{IN}}=\frac{L_{1} L_{2}}{C_{\mathrm{P} 1} C_{\mathrm{P} 2} \omega^{2} M^{2} R_{\mathrm{AC}}} .
$$

The input current $I_{\mathrm{IN}}$ and output current $I_{\mathrm{O}}$ can be expressed as follows:

$$
\left\{\begin{array}{l}
I_{\mathrm{IN}}=\frac{U_{\mathrm{IN}} C_{\mathrm{P} 1} C_{\mathrm{P} 2} \omega^{2} M^{2} R_{\mathrm{AC}}}{L_{1} L_{2}} \\
I_{\mathrm{O}}=\frac{M U_{\mathrm{IN}}}{j \omega L_{1} L_{2}} .
\end{array}\right.
$$

As indicated by Equation (6), $I_{\mathrm{O}}$ only depends on $U_{\mathrm{IN}}$, the operating angular frequency $\omega$, and the compensation inductance parameters $L_{1}$ and $L_{2}$. Therefore, the DS-LCC compensation topology can be equivalent to a current source, realizing the $\mathrm{CC}$ charging mode.

The transconductance gain $G_{U I}$ of the DS-LCC compensation topology can be derived as follows:

$$
G_{\mathrm{UI}}=\left|\frac{I_{\mathrm{O}}}{U_{\mathrm{IN}}}\right|=\frac{M}{j \omega L_{1} L_{2}} .
$$

According to Equations (2) and (7), the input phase angle $Q_{\mathrm{IN}}$ of the input equivalent impedance and transconductance gain $G_{U I}$ of the DS-LCC WPT charging systems are plotted in Figure 5, respectively. The diagrams of the transconductance gain $G_{U I}$, which are regarded as the absolute value of the ratio of $I_{\mathrm{O}}$ to $U_{\mathrm{IN}}$. As shown in Figure $5 \mathrm{a}$, the constant $G_{U I}$ under the ZPA can be realized at the fixed frequency of $85 \mathrm{kHz}$, and the input phase angle of the associated input impedance against the effect of the dynamic loads. As shown in Figure 5, it can be seen that the DS-LCC compensation topology can also achieve constant current output under ZPA conditions at the frequency of $110 \mathrm{kHz}$, but the slope of the transconductance gain curve at $110 \mathrm{kHz}$ was significantly higher than the slope at $85 \mathrm{kHz}$. Therefore, changes in the output current at $110 \mathrm{kHz}$ were more sensitive to changes in the switching frequency than at $85 \mathrm{kHz}$. A small variation in frequency around $110 \mathrm{kHz}$ could cause a significant change in the output current. In addition, the variation of the phase according to the switching frequency change at $110 \mathrm{kHz}$ was larger than that at $85 \mathrm{kHz}$. Therefore, this article selected $85 \mathrm{kHz}$ as the operating frequency. 


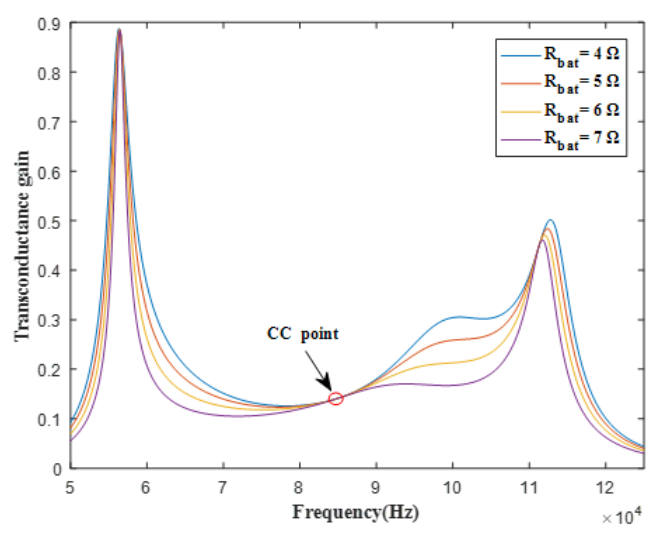

(a)

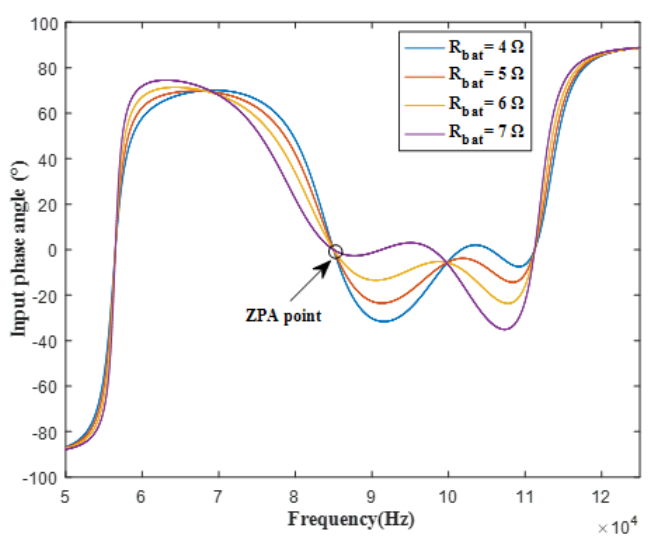

(b)

Figure 5. (a) Transconductance gain of the DS-LCC topology; (b) input phase angle of the input equivalent impedance.

Additionally, it is worth noting that if the compensation parameters satisfy complex constraint conditions, the DS-LCC topology can implement CV-output by using the frequency-hopping under the conditions of ZPA [27]. However, frequency-hopping leads to the following issues:

(1) Iteration is needed to determine the CV-output point of attachment of the parameter settings, which leads to a high required accuracy of the compensation parameters;

(2) Under the resonant condition, the WPT systems are highly sensitive to changes in the coupling parameters of the LCT. If the coupling parameters change, the ZPA conditions cannot be realized in the $\mathrm{CV}$ output stage;

(3) The increment of the working frequency inevitably increases the loss of the WPT system and can even lead to frequency bifurcation;

(4) The operating frequency of the system is limited by relevant standards; thus, it cannot be improved in a wide range.

Therefore, this article analyzes the existing compensation topology that can realize the CV-output. It is found that the high-order compensation topology LCC-S can realize a load-independent CV-output. Next, a systematic theoretical analysis of the LCC-S topology is performed.

\subsection{Implementation of $C V$ Mode with $Z P A$ Condition}

The LCC-S topology has received considerable attention for its ability to provide a stable CV-output characteristic under dynamic loads. The circuit diagram of the LCC-S compensation topology is presented in Figure 6, where the $C_{\mathrm{FF}}$ represents the $C_{\mathrm{F} 3}$ and $L_{2}$ in parallel, and in series with $C_{\mathrm{F} 2}$, which is described in detail in Section 3. The composition of the primary side of the LCC-S topology is the same as that of the DS-LCC compensation topology, which can generate a constant current in the transmitting coil. The difference between the two topologies is that the secondary side is a resonant network composed of $L_{\mathrm{S}}$ and $C_{\mathrm{FF}}$ in series.

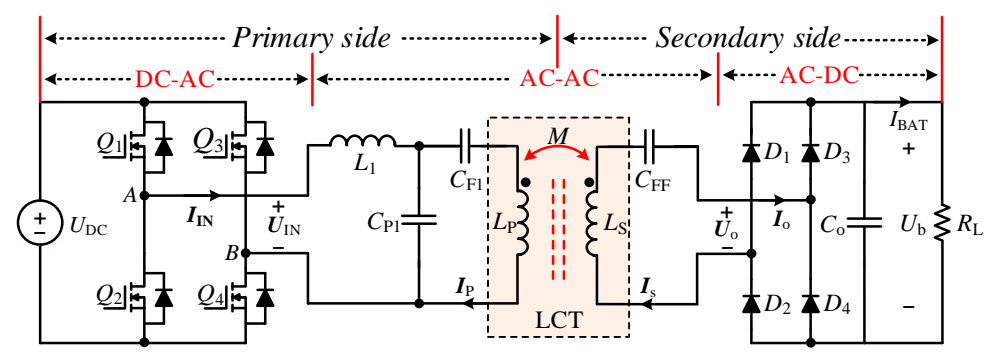

Figure 6. LCC-S compensated WPT charging systems. 
The M-type model analysis method is also applicable to the analysis of the LCC-S compensation topology. According to the foregoing analysis, the $M$-type model is applied to investigate the LCC-S compensation topology, as shown in Figure 7.

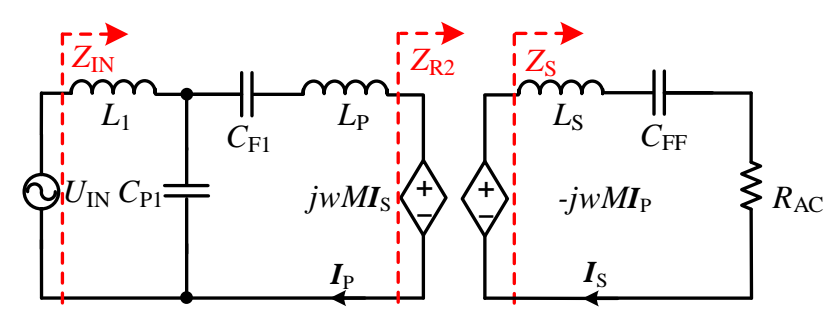

Figure 7. Equivalent $M$-type model of the LCC-S compensation topology for the CV-output.

To intuitively study the LCC-S compensation topology, the equivalent $M$-type model in Figure 7 can be converted into the model, as shown in Figure 8.

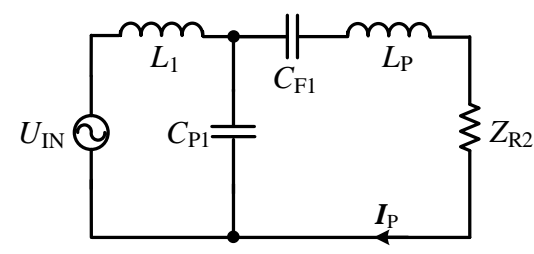

Figure 8. Primary side circuit diagram of the LCC-S topology with reflected impedance.

The equivalent impedance $Z_{S}$ and the reflection impedance $Z_{R 2}$ of the secondary side can be derived as follows:

$$
\left\{\begin{array}{l}
Z_{\mathrm{S}}=j \omega L_{\mathrm{S}}+\frac{1}{j \omega C_{\mathrm{FF}}}+R_{\mathrm{AC}} \\
Z_{\mathrm{R} 2}=\frac{w^{2} M^{2}}{Z_{\mathrm{S}}}
\end{array}\right.
$$

The input equivalent impedance $Z_{\mathrm{IN}}$ and the input phase angle $Q_{\mathrm{IN}}$ can be represented as follows:

$$
\left\{\begin{array}{l}
Z_{\mathrm{IN}}=j \omega L_{1}+\frac{1}{j \omega C_{\mathrm{P} 1}} \|\left(j \omega L_{\mathrm{P}}+\frac{1}{j \omega C_{\mathrm{F} 1}}+Z_{\mathrm{R} 2}\right) \\
Q_{\mathrm{IN}}=\frac{180^{\circ}}{\pi} \arctan \frac{I_{\mathrm{m}}\left(Z_{\mathrm{IN}}\right)}{R_{\mathrm{e}}\left(Z_{\mathrm{IN}}\right)} .
\end{array}\right.
$$

According to [27], when the operating angular frequency is operated at $\omega_{\mathrm{CV}}=$ $1 / \sqrt{L_{1} C_{\mathrm{P} 1}}=1 / \sqrt{C_{\mathrm{F} 1}\left(L_{\mathrm{P}}-L_{1}\right)}=1 / \sqrt{L_{\mathrm{S}} C_{\mathrm{FF}}}$, the input equivalent impedance $Z_{\mathrm{IN}}$ can be rewritten as (10):

$$
Z_{\mathrm{IN}}=\frac{\omega^{2} C_{\mathrm{F} 1} L_{1} R_{\mathrm{AC}}}{j \omega\left(L_{\mathrm{P}}-L_{1}-\frac{1}{\omega^{2} C_{\mathrm{F} 1}}\right) R_{\mathrm{AC}}+\omega^{4} M^{2} C_{\mathrm{P} 1} C_{\mathrm{F} 1}} .
$$

To achieve soft switching in the ZPA condition, it is required that the imaginary part of the Equation (10) must be equal to zero, which can be expressed as (11):

$$
L_{1}=\frac{C_{\mathrm{F} 1}}{C_{\mathrm{F} 1}+C_{\mathrm{P} 1}} L_{\mathrm{P}}
$$

As indicated from the Equation (10), $Z_{\mathrm{IN}}$ can be rewritten as (12):

$$
Z_{\mathrm{IN}}=\frac{L_{1}^{2}}{M^{2}} R_{\mathrm{AC}}
$$


The input and output currents of the LCC-S topology can be represented as (13):

$$
\left\{\begin{array}{l}
I_{\mathrm{IN}}=\frac{U_{\mathrm{IN}}}{Z_{\mathrm{IN}}}=\frac{U_{\mathrm{IN}} M^{2}}{L_{1}^{2} R_{\mathrm{AC}}} \\
I_{\mathrm{P}}=\frac{U_{\mathrm{IN}}}{j \omega L_{1}} \\
I_{\mathrm{O}}=\frac{j \omega M I_{\mathrm{P}}}{Z_{\mathrm{S}}}=\frac{U_{\mathrm{IN}} M}{L_{1} R_{\mathrm{AC}}} .
\end{array}\right.
$$

The input voltage $U_{\mathrm{O}}$ of the rectifier and the voltage transfer gain $G_{\mathrm{UU}}$ can be represented as:

$$
\left\{\begin{array}{l}
U_{\mathrm{O}}=I_{\mathrm{O}} R_{\mathrm{AC}}=\frac{M U_{\mathrm{IN}}}{L_{1}} \\
G_{\mathrm{UU}}=\left|\frac{U_{\mathrm{O}}}{U_{\mathrm{AB}}}\right|=\frac{M}{L_{1}} .
\end{array}\right.
$$

Figure $9 \mathrm{a}, \mathrm{b}$ is based on Equations (9) and (14), respectively. The LCC-S compensation topology can implement $\mathrm{CV}$ charging mode under ZPA conditions, regardless of the battery equivalent resistance, which varies from 7 to $40 \Omega$, as shown in Figure 9a. Moreover, the gradient of the voltage transfer gain $G_{U U}$ line at approximately $85 \mathrm{kHz}$ is insensitive to the change of the working frequency, indicating the LCC-S compensation topology can provide a stable CV-output over a wide frequency range. As shown in Figure $9 b$, when the operating frequency is less than the resonant frequency, $Q_{\text {IN }}$ is positive under high load conditions, indicating that the system presents inductive, but when the operating frequency is greater than the resonant frequency, $Q_{\mathrm{IN}}$ is negative under high load conditions, indicating that the system shows capacitive. It is worth noting that $Q_{\mathrm{IN}}$ has three ZPA points when $R_{\mathrm{L}}=7 \Omega$, indicating that the system first appears as capacitive and then appears as inductive near the resonance frequency point. Therefore, in order to ensure the soft-switching of the AC switch, the parameter design of compensated inductance $L_{1}$ is designed to make the actual value slightly greater than the theoretical value.

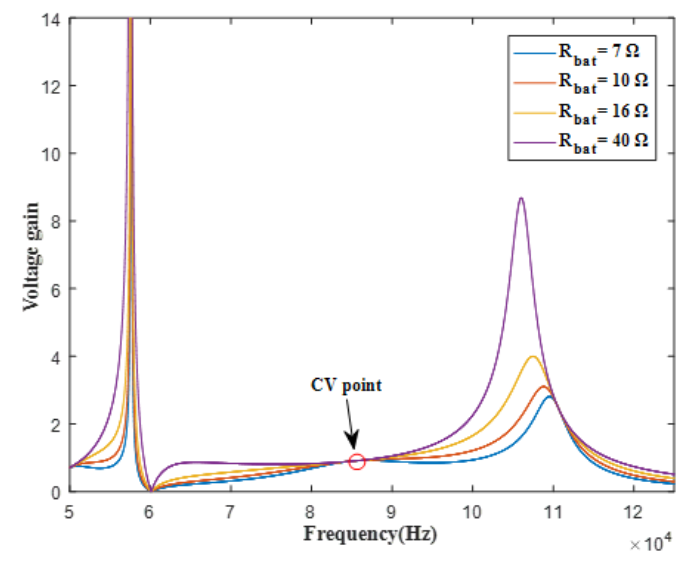

(a)

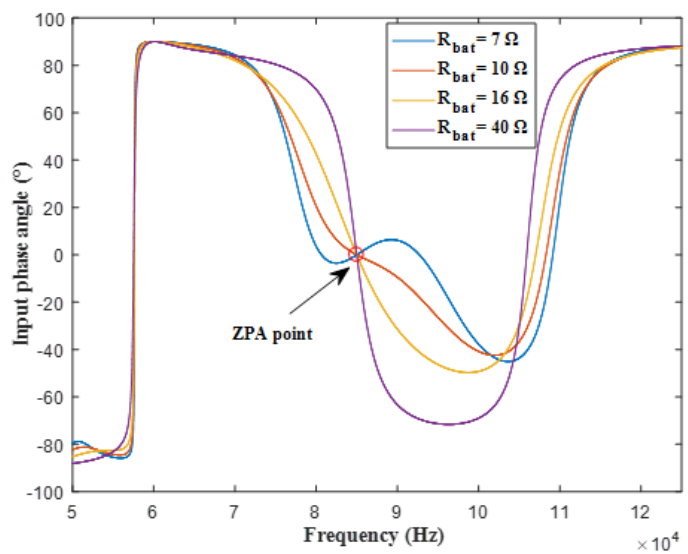

(b)

Figure 9. (a) Voltage gain of the LCC-S topology and (b) phase angle of the input impedance.

\section{Proposed CC and CV Charging Modes and Parameter Modification}

\subsection{Proposed CC and CV Charging Modes}

According to the foregoing theoretical analysis, under the constraints of the ZPA conditions, the DS-LCC topology can realize a stable CC charging mode, and the LCC-S topology can implement a CV charging mode under dynamic loads.

Clearly, by combining the transfer characteristics of the two topologies and adopting reasonable switching control logic, a charger that can satisfy the $\mathrm{CC} / \mathrm{CV}$ modes of the battery can be obtained. Therefore, this paper proposed a hybrid compensation topology by employing a shunt auxiliary capacitor $C_{\mathrm{F} 3}$ and two additional ACSs $\left(S_{1}\right.$ and $\left.S_{2}\right)$ on the secondary side to achieve onboard charging, as shown in Figure 10. 


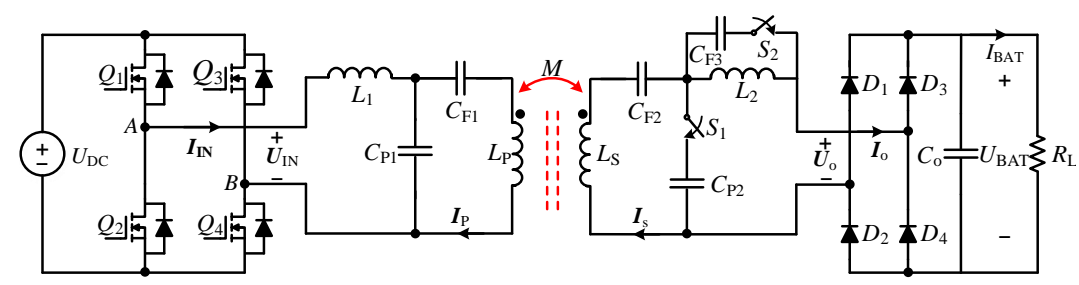

(a)

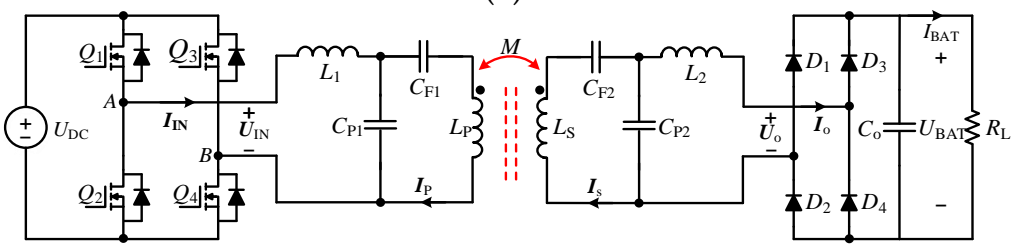

(b)

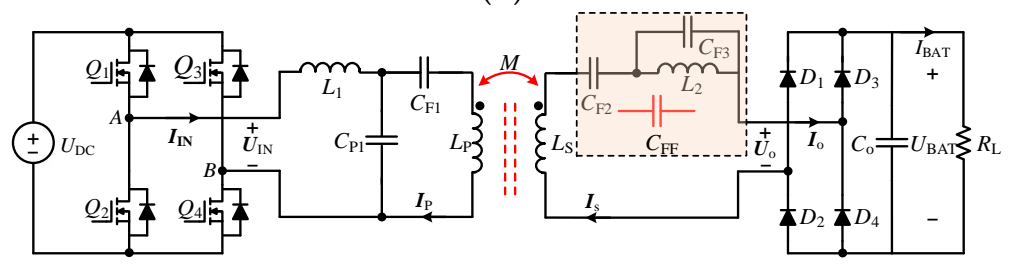

(c)

Figure 10. (a) Proposed hybrid compensation topology of the WPT systems; (b) DS-LCC topology for the CC output; (c) LCC-S topology for the CV output.

The two additional ACSs $\left(S_{1}\right.$ and $\left.S_{2}\right)$ in the designed hybrid topology are shown in Figure 11. In general, ACSs can be designed via two MOSFETs connected back-to-back.

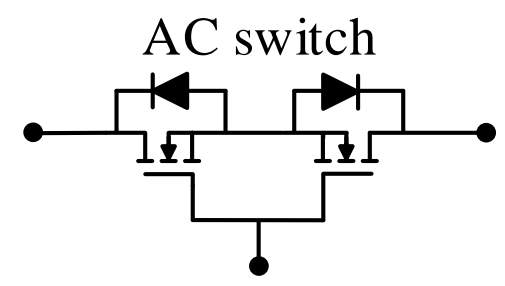

Figure 11. ACSs with two MOSFETs connected back-to-back.

As clearly shown in Figure 12a, the control logic of ACSs $S_{1}$ and $S_{2}$ of the battery charger is converted from the $\mathrm{CC}$ to $\mathrm{CV}$ charging mode. Figure $12 \mathrm{~b}$ represents the circuit diagram for performing the switching action. $U_{\mathrm{BAT}}$ represents the charging voltage of the battery, and $k_{\mathrm{V}}=U_{\mathrm{REF}} / U_{\mathrm{BAT}} \mathrm{MAX}$ represents the ratio of the reference voltage $U_{\mathrm{REF}}$ and the boundary voltage from CC to CV mode. Initially, the WPT charger operates in CC

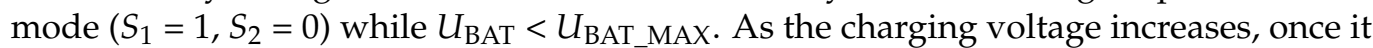

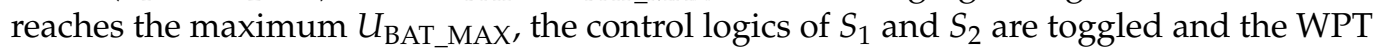
charger is operating in CV mode $\left(S_{1}=0, S_{2}=1\right)$, and $I_{\mathrm{BAT}}$ begins to drop until the charge end current is reached.

Throughout the charging process, when the output voltage of the charger is less than $U_{\mathrm{BAT}}$, switch $S_{1}$ is connected and switch $S_{2}$ is disconnected, and the WPT charging systems operate in the CC stage, as clearly shown in Figure 10b. In contrast, when the output voltage increases to $U_{\mathrm{BAT}}, S_{1}$ is disconnected and $S_{2}$ is connected, and the WPT charging systems operate in the CV charging stage, as shown in Figure 10c. 


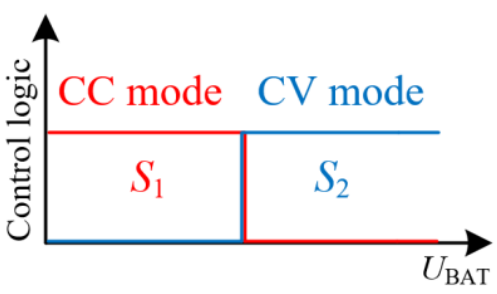

(a)

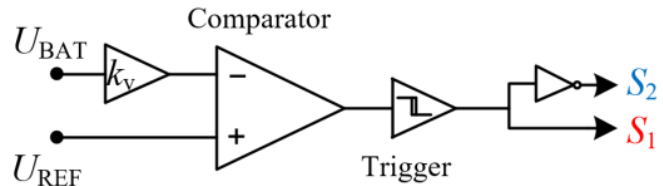

(b)

Figure 12. (a) Control logic for $S_{1}$ and $S_{2}$ of the battery charger and (b) circuit diagram for performing the switching action.

\subsection{The Parameter Modification}

On the primary side of the WPT charging systems, the input voltage can be modulated by the FBI into a square wave voltage with a $0.5-\mathrm{T}$ duty cycle. Assuming the output voltage $U_{\text {IN }}$ is expanded by the Fourier series, it can be expressed as:

$$
U_{\mathrm{IN}}=\frac{4 U_{\mathrm{DC}}}{\pi} \sum_{n=1,3,5 \ldots} \frac{\sin (n \varphi)}{n} .
$$

where $n$ is the number of harmonics and $\varphi$ is the phase angle. Because the quality factor of the resonance compensation topology is quite high in the WPT system, the $I_{\mathrm{IN}}$ current component corresponding to the super-harmonics are very small. Therefore, fundamental harmonic analysis can be used without affecting accuracy. If only the fundamental component is considered, $n=1$, the relationships between the input DC source and root-meansquare (RMS) values of the output voltage $U_{\mathrm{IN}}$ and current $I_{\mathrm{IN}}$ of FBI can be expressed as the following equation according to [30]:

$$
U_{\mathrm{IN}}=\frac{2 \sqrt{2}}{\pi} U_{\mathrm{DC}}, I_{\mathrm{IN}}=\frac{2 \sqrt{2}}{\pi} I_{\mathrm{DC}} .
$$

The secondary side, due to the output low-pass filter, is only composed of capacitance. Thus, the RMS input voltage $U_{\mathrm{O}}$ of the rectifier, and the connection between the charging current $I_{\mathrm{BAT}}$ of the battery charger and the RMS input current $I_{\mathrm{O}}$ of the rectifier can be derived according to [26], which is represented as (17):

$$
U_{\mathrm{O}}=\frac{2 \sqrt{2}}{\pi} U_{\mathrm{BAT}}, I_{\mathrm{BAT}}=\frac{2 \sqrt{2}}{\pi} I_{\mathrm{O}} .
$$

According to (17), the rectifier output resistance $R_{\mathrm{L}}$ can be expressed as (18):

$$
R_{\mathrm{L}}=\frac{\pi^{2}}{8} R_{\mathrm{AC}} .
$$

The parameter adjustment process of the proposed WPT systems typically includes two steps: First, the compensation inductors $L_{1}$ and $L_{2}$ are designed according to the CC-output $I_{\mathrm{BAT}}$ and the rated output power $P_{\mathrm{O}}$ required by the DS-LCC compensation topology. $L_{1}$ and $L_{2}$ symmetric design by using traditional tuning method [20] can be expressed as (19):

$$
L_{1}=L_{2}=\frac{\pi \sqrt{2} M U_{\mathrm{IN}}}{4 U_{\mathrm{BAT}}} .
$$

Here, $M=k \sqrt{L_{\mathrm{P}} L_{\mathrm{S}}}$, by substituting Equation (16) into (19), $L_{1}$ and $L_{2}$ can be rewritten as follows:

$$
L_{1}=L_{2}=\frac{k \sqrt{L_{\mathrm{P}} L_{\mathrm{S}}} U_{\mathrm{DC}}}{U_{\mathrm{BAT}}} .
$$


Second, all the compensation capacitors can be determined according to the given resonance conditions.

$$
\begin{gathered}
C_{\mathrm{P} 1}=\frac{1}{\omega_{0}^{2} L_{1}}, C_{\mathrm{P} 2}=\frac{1}{\omega_{0}^{2} L_{2}}, C_{\mathrm{F} 1}=\frac{1}{\omega_{0}^{2}\left(L_{\mathrm{P}}-L_{1}\right)}, \\
C_{\mathrm{F} 2}=\frac{1}{\omega_{0}^{2}\left(L_{\mathrm{S}}-L_{1}\right)}, C_{\mathrm{FF}}=\frac{1}{\omega_{0}^{2} L_{\mathrm{S}}} .
\end{gathered}
$$

On the secondary side of the LCC-S compensation topology, the sum of the impedances of $C_{\mathrm{F} 2}, C_{\mathrm{F} 3}$, and $L_{2}$ should be the same as the impedance value $C_{\mathrm{FF}}$, as shown in Figure 10c.

$$
\frac{1}{j \omega C_{\mathrm{FF}}}=\frac{1}{j \omega C_{\mathrm{F} 2}}+\frac{1}{j \omega C_{\mathrm{F} 3}} \| j \omega L_{2} .
$$

According to Equations (21) and (22), the capacitance of $C_{\mathrm{F} 3}$ can be expressed as:

$$
C_{\mathrm{F} 3}=\frac{1}{L_{2} \omega_{0}^{2}}-\frac{C_{\mathrm{FF}} C_{\mathrm{F} 2}}{C_{\mathrm{FF}}-C_{\mathrm{F} 2}} .
$$

As indicated by Equations (15)-(23), the compensation capacitance and inductance values of the WPT charging systems can be obtained. In order to more clearly present the parameters design procedure of the proposed hybrid compensation topology is shown in Figure 13.

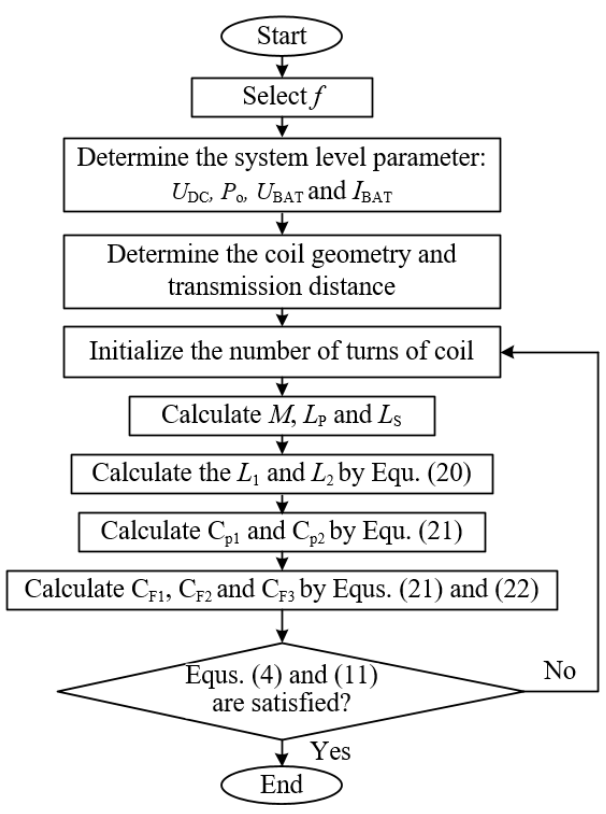

Figure 13. Flowchart for the topology parameters design of the proposed WPT charger.

Moreover, the proposed high-order hybrid compensation topology has high degree of freedom, and by designing compensation parameters of the WPT charging systems can yield different levels of charging current and charging voltage within a certain range.

\section{Experiment Verification}

It is necessary to confirm the feasibility of the proposed WPT charging systems. To validate the foregoing theoretical analysis results and the proposed hybrid compensation topology model, a 1.1-kW test prototype was constructed, as shown in Figure 14, according to the structure of Figure 10a. The specific parameter settings were presented in Table 1, and were measured by using the LCR meter (IM3536, Hioki). The parameter settings of this experimental prototype provided a CC-output of $11.8 \mathrm{~A}$ and a CV-output of $88 \mathrm{~V}$. As indicated in Figure 14, DSP TMS320F28335 was selected in this experiment to control FBI and ACSs $S_{1}$ and $S_{2}$ composed of SiC MOSFETs (C3M0030090K, Wolfspeed), and Schottky 
diodes (IDW20G120C5B) were used to form the rectifier. Chroma 63200A was adopted to simulate the dynamic loads.

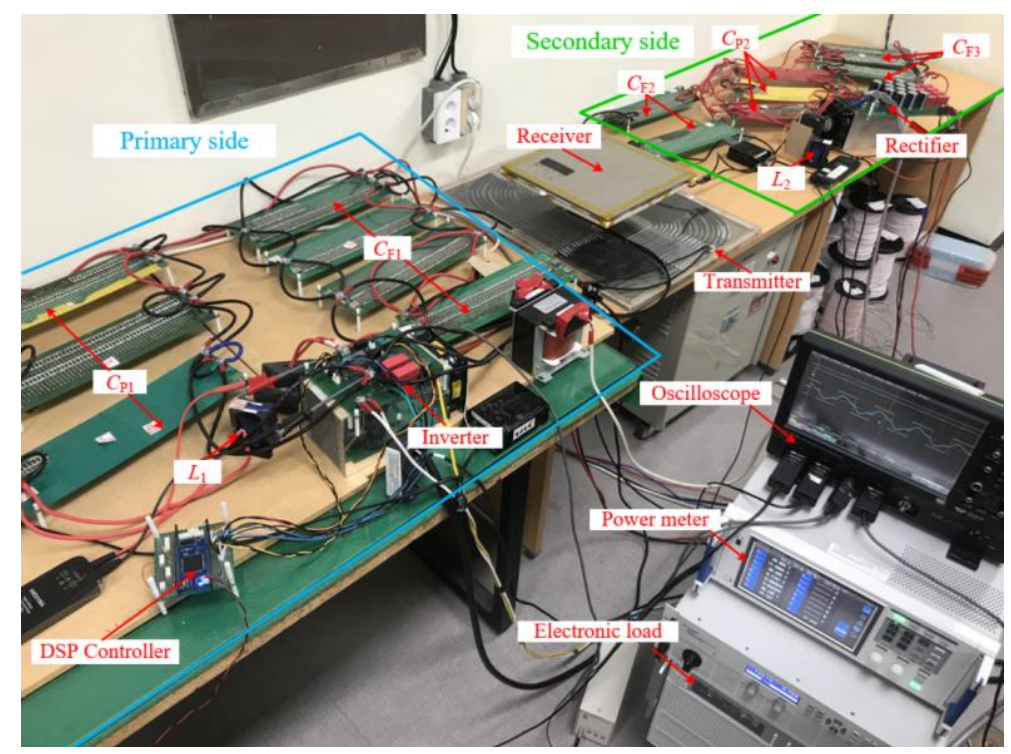

Figure 14. Experimental prototype of the proposed WPT battery charger.

Table 1. Designed parameters of the proposed WPT charger.

\begin{tabular}{cccc}
\hline Symbols & Symbols & Symbols & Symbols \\
\hline$U_{\mathrm{IN}}$ & $100 \mathrm{~V}$ & $L_{1}$ & $11.51 \mathrm{uH}$ \\
$f$ & $85 \mathrm{kHz}$ & $L_{2}$ & $11.48 \mathrm{uH}$ \\
$C_{\mathrm{F} 1}$ & $122.9 \mathrm{nF}$ & $C_{\mathrm{P} 1}$ & $305.7 \mathrm{nF}$ \\
$C_{\mathrm{F} 2}$ & $123.8 \mathrm{nF}$ & $C_{\mathrm{P} 2}$ & $305.9 \mathrm{nF}$ \\
$C_{\mathrm{F} 3}$ & $610.48 \mathrm{nF}$ & & \\
\hline
\end{tabular}

In this experimental prototype, the measured parameters of manufactured LCT are presented in Table 2. These parameters met the requirements of the WPT1 standard of SAE J2954 recommended practices. There was a deviation of approximately $1 \%$ between the actual measured value and the theoretical value due to manufacturing deviations. The dimensions (length $\times$ width) of the transmitting-loop $L_{\mathrm{P}}$ and receiving-loop $L_{S}$ were $65 \times 50 \mathrm{~cm}$ and $32 \times 32 \mathrm{~cm}$, respectively. The transmission distance between the $L_{\mathrm{P}}$ and $L_{S}$ was $15 \mathrm{~cm}$. Litz wire was used to reduce the skin effect and proximity effect.

Table 2. Measured LCT parameters.

\begin{tabular}{cccc}
\hline Symbols & Symbols & Symbols & Symbols \\
\hline$k$ & 0.267 & $M$ & $10.75 \mathrm{uH}$ \\
$L_{\mathrm{P}}$ & $40.8 \mathrm{uH}$ & $R_{\mathrm{P}}$ & $13.31 \mathrm{~m} \Omega$ \\
$L_{\mathrm{S}}$ & $39.9 \mathrm{uH}$ & $R_{\mathrm{S}}$ & $23.65 \mathrm{~m} \Omega$ \\
\hline
\end{tabular}

The overall charging curve of the battery is presented in Figure 15a. As shown, in the CC charging stage, the output voltage increased from 24 to $88 \mathrm{~V}$ as the equivalent resistance increased from 2 to $7.3 \Omega$ (orange line). In contrast to the equivalent resistance, which changed by a factor of 2.6 , the charging current changed by only $2.6 \%$, indicating the realization of the $\mathrm{CC}$ mode. In the $\mathrm{CV}$ charging stage, the output current decreased from 11.8 to $1.9 \mathrm{~A}$ as the equivalent resistance increased from 7.3 to $45.9 \Omega$. In contrast to the equivalent resistance, which changed by a factor of 6.3 , the charging voltage changed by only $5.5 \%$, indicating the realization of the $\mathrm{CV}$-output. Figure $15 \mathrm{~b}$ presents the measured 
experimental efficiency of the proposed hybrid compensation WPT systems under the dynamic loads in the total process (blue line). In the CC charging stage, the maximum efficiency of the entire system was $90.9 \%$. When the rated charging voltage value was reached, the WPT charger switched to the CV charging mode. The system efficiency gradually increased from $90 \%$ to the maximum value of $91 \%$ and then gradually decreased to $85 \%$.

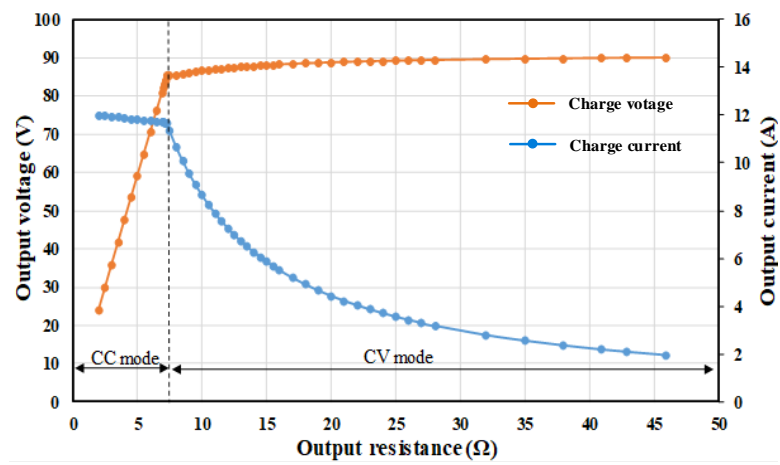

(a)

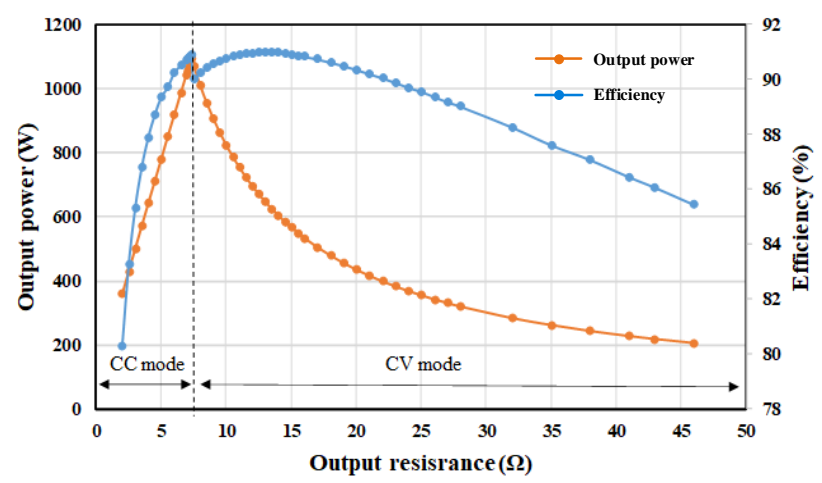

(b)

Figure 15. Measured charging process under dynamic loads. (a) Charging diagram; (b) charging efficiency and output power.

The experimental waveforms were scanned by using an oscilloscope (HDO4034A, Teledyne LeCroy). The results obtained under the dynamic loads are presented in Figures 16 and 17. In the $C C$ mode, the charging current $I_{\mathrm{BAT}}$ was basically constant while the output resistance $R_{\mathrm{L}}$ fluctuated from 4 to $7 \Omega$, as presented in Figure 16, and the charging voltage $U_{\mathrm{BAT}}$ and AC input current $I_{\mathrm{IN}}$ increased continuously. In contrast, in the CV charging stage, as shown in Figure 17 , when $R_{\mathrm{L}}$ fluctuated from 8 to $11 \Omega$, the charging voltage $U_{\text {BAT }}$ was nearly unchanged, $I_{\mathrm{BAT}}$ and $I_{\mathrm{IN}}$ continued to decrease over time. In both the CC and CV charging stages, $U_{\mathrm{IN}}$ was ahead of $I_{\mathrm{IN}}$ by a small phase angle to achieve the ZVS of FBI, which reduces reactive power loss of the WPT system.

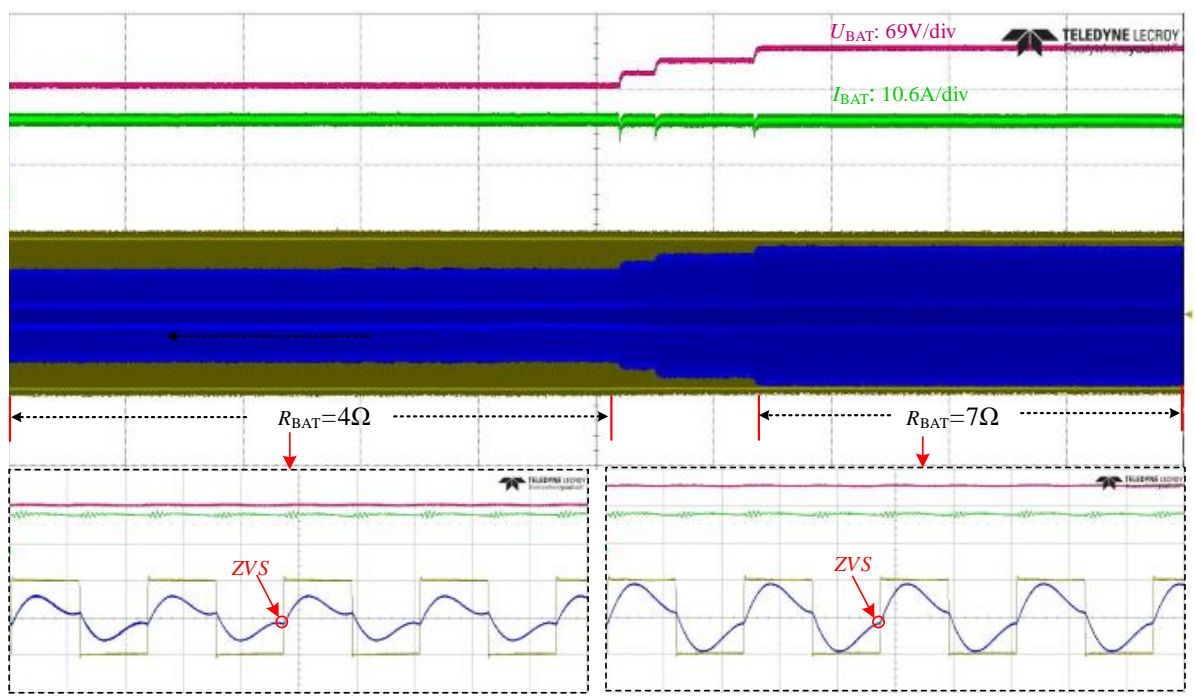

Figure 16. Experimental waveforms of $U_{\mathrm{BAT}}, I_{\mathrm{BAT}}, U_{\mathrm{IN}}$, and $I_{\mathrm{IN}}$ in the DS-LCC topology. 


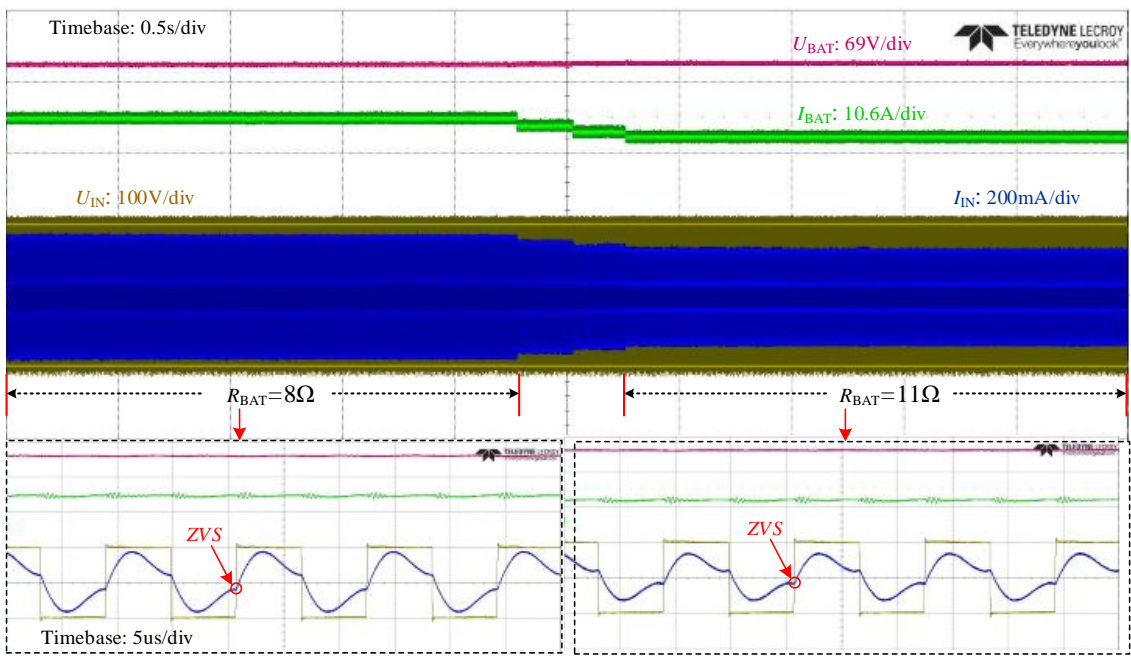

Figure 17. Experimental waveforms of $U_{\mathrm{BAT}}, I_{\mathrm{BAT}}, U_{\mathrm{IN}}$, and $I_{\mathrm{IN}}$ in the LCC-S topology.

The output performance of the CC and CV modes under dynamic loads were shown in Figures 18 and 19. When the WPT system worked in the CC charging stage, $U_{\mathrm{BAT}}$ decreased from 81 to $47 \mathrm{~V}$ and then increased to $81 \mathrm{~V}$ and $R_{\mathrm{L}}$ varied between 4 and $7 \Omega$, as shown in Figure 18. The results indicated that $I_{\mathrm{BAT}}$ was stable at $11.8 \mathrm{~A}$, satisfying the CC-output requirements. Figure 19 presented the waveforms for the $\mathrm{CV}$ charging mode. As shown, the output current increased from 7.9 to $10.7 \mathrm{~A}$ and then decreased to $7.9 \mathrm{~A}$, and $R_{\mathrm{L}}$ varied from 8 to $11 \Omega$. The output voltage was stable at $88.3 \mathrm{~V}$, satisfying the $\mathrm{CV}$ output requirements. The experimental results are consistent with the theoretical analysis results.

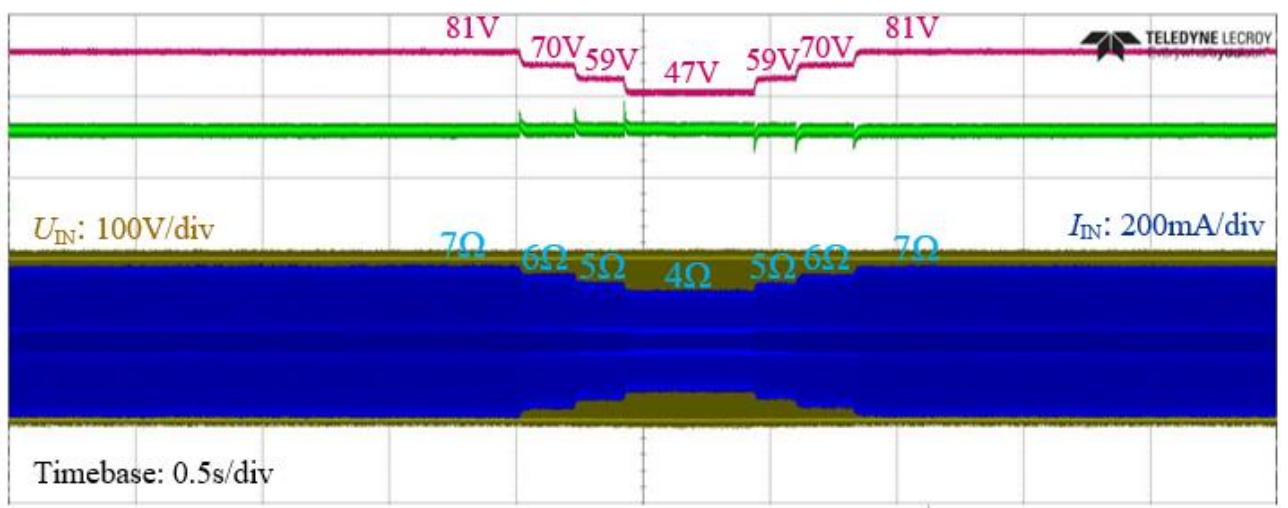

Figure 18. Experimental dynamic response waveforms of multi-load regulation in the CC mode.

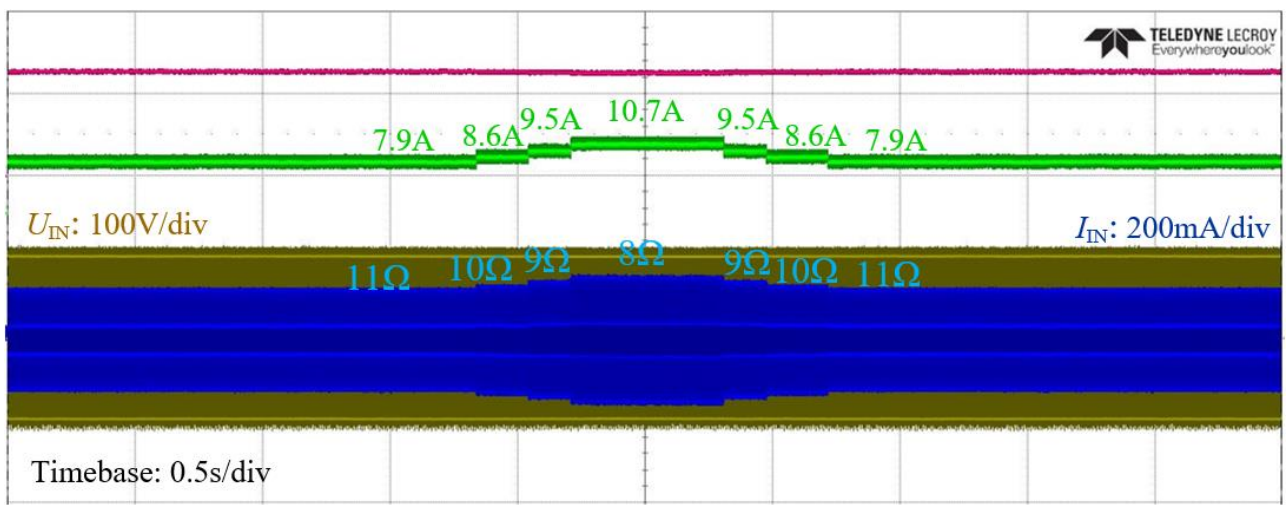

Figure 19. Experimental dynamic response waveforms of multi-load regulation in the CV mode. 
It is necessary to evaluate the transient response of the proposed WPT charging systems throughout the switching process. Figure 20 depicts the transient waveforms of $U_{\mathrm{IN}}, I_{\mathrm{IN}}, U_{\mathrm{BAT}}$, and $I_{\mathrm{BAT}}$ when ACSs $S_{1}$ was turned off and $S_{2}$ was turned on. As shown in Figure 20, the throughout transition process from the CC to CV charging mode, $U_{\mathrm{IN}}$ always remained unchanged, whereas the $I_{I N}$ in the $C V$ mode was slightly larger than that in the CC mode. Throughout the charging process of the battery, $U_{\mathrm{BAT}}$ and $I_{\mathrm{BAT}}$ remained essentially constant. The whole switching process took approximately $80 \mathrm{~ms}$ to restore stability, which is short compared with entire charging process of few hours, and the impact of mode switching on the whole charging process can be ignored. The foregoing experimental results verify the feasibility of the proposed hybrid wireless power transfer charger.

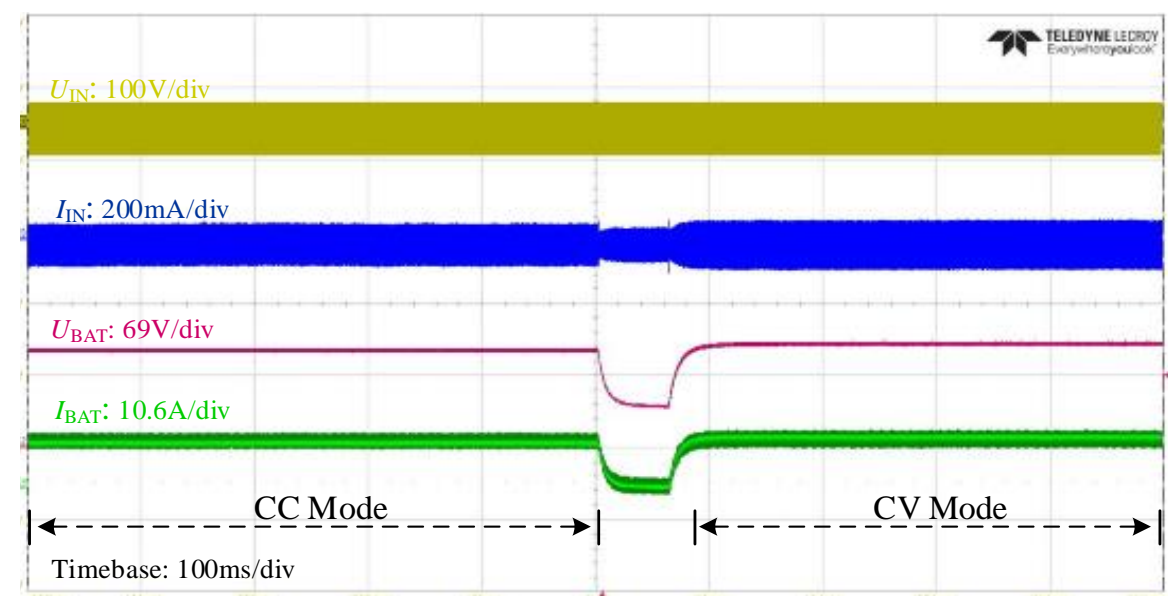

Figure 20. Transient waveforms switching process from the $C C$ to $C V$ charging mode for $U_{\mathrm{IN}}, I_{\mathrm{IN}}$, $U_{\mathrm{BAT}}$, and $I_{\mathrm{BAT}}$.

\section{Conclusions}

The DS-LCC and LCC-S compensation topologies of the WPT systems were analyzed using a mutual inductance model. By combining the advantages of their respective CC and CV outputs, a shunt capacitor, and two ACSs were added on the secondary side, and a switch hybrid compensation topology was proposed. The proposed hybrid topology charger is designed to easily implement the ZPA feature, which contributes to reduce the VA ratio and enhance the WPT systems efficiency. Moreover, the control was applied directly to the secondary side, which avoids sophisticated control logic and is conducive to the robustness of the WPT systems. Additionally, the working frequency of the WPT systems was fixed throughout the charging process, which mitigates the problems caused by frequency hopping. Finally, a 1.1-kW experimental prototype was designed to validate the charging performance of the proposed WPT systems. The results of experimental indicated the proposed switching hybrid compensation topology can well accomplish CC and CV outputs under dynamic loads, and the maximum charging efficiencies were $90.9 \%$ and $91 \%$, respectively. The experimental results were consistent with those of the theoretical analysis.

Author Contributions: Conceptualization, G.L. and D.-H.K.; data curation, G.L.; formal analysis, G.L.; funding acquisition, D.-H.K.; investigation, G.L. and D.-H.K.; project administration, D.-H.K.; writing—original draft, G.L.; writing—review and editing, D.-H.K. All authors have read and agreed to the published version of the manuscript.

Funding: This work was supported in part by Basic Science Research Program through the National Research Foundation of Korea (NRF) funded by the Ministry of Education under Grant 2020R1I1A3073169, in part by the Korea Institute of Energy Technology Evaluation and Planning (KETEP), and in part by the Ministry of Trade, Industry, and Energy (MOTIE) of the Republic of Korea under Grant 2019381010001B. 
Institutional Review Board Statement: Not applicable.

Informed Consent Statement: Not applicable.

Data Availability Statement: Not applicable.

Conflicts of Interest: The authors declare no conflict of interest.

\section{References}

1. Bil, C.; Simic, M.; Vojisavljevic, V. Design of a recharge station for UAVS using non-contact wireless power transfer. In Proceedings of the 54th AIAA Aerospace Sciences Meeting, San Diego, CA, USA, 4-8 January 2016; p. 1525.

2. Liu, C.; Jiang, C.; Song, J.; Chau, K.T. An effective sandwiched wireless power transfer system for charging implantable cardiac pacemaker. IEEE Trans. Ind. Electron. 2019, 66, 4108-4117. [CrossRef]

3. Xiao, C.; Cheng, D.; Wei, K. An LCC-C compensated wireless charging system for implantable cardiac pacemakers: Theory, experiment, and safety evaluation. IEEE Trans. Power Electron. 2018, 33, 4894-4905. [CrossRef]

4. Fukuda, H.; Kobayashi, N.; Shizuno, K.; Yoshida, S.; Tanomura, M.; Hama, Y. New concept of an electromagnetic usage for contactless communication and power transmission in the ocean. In Proceedings of the 2013 IEEE International Underwater Technology Symposium (UT), Tokyo, Japan, 5-8 March 2013; pp. 1-4.

5. Hui, S.Y. Planar wireless charging technology for portable electronic products and Qi. Proc. IEEE 2013, 101, 1290-1301. [CrossRef]

6. Jang, Y.; Jovanovic, M.M. A contactless electrical energy transmission system for portable-telephone battery chargers. IEEE Trans. Ind. Electron. 2003, 50, 520-527. [CrossRef]

7. Li, S.; Mi, C.C. Wireless power transfer for electric vehicle applications. IEEE J. Emerg. Sel. Top. Power Electron. $2015,3,4-17$.

8. Wu, H.H.; Gilchrist, A.; Sealy, K.D.; Bronson, D. A high efficiency $5 \mathrm{~kW}$ inductive charger for EVs using dual side control. IEEE Trans. Ind. Informat. 2012, 8, 585-595. [CrossRef]

9. Ahn, D.; Kim, S.; Moon, J.; Cho, I.-K. Wireless power transfer with automatic feedback control of load resistance transformation. IEEE Trans. Power Electron. 2016, 31, 7876-7886. [CrossRef]

10. Li, H.; Li, J.; Wang, K.; Chen, W.; Yang, X. A maximum efficiency point tracking control scheme for wireless power transfer systems using magnetic resonant coupling. IEEE Trans. Power Electron. 2015, 30, 3998-4008. [CrossRef]

11. Vu, V.B.; Tran, D.H.; Choi, W. Implementation of the constant current and constant voltage charge of inductive power transfer systems with the double-sided LCC compensation topology for electric vehicle battery charge applications. IEEE Trans. Power Electron. 2018, 33, 7398-7410. [CrossRef]

12. Yang, L.; Li, X.; Liu, S.; Cai, C.S. Analysis and design of an LCCC/S-compensated WPT system with constant output characteristics for battery charging applications. IEEE J. Emerg. Sel. Top. Power Electron. 2015, 9, 1169-1180. [CrossRef]

13. Byeon, J.; Kang, M.; Kim, M.; Joo, D.-M.; Lee, B.K. Hybrid control of inductive power transfer charger for electric vehicles using LCCL-S resonant network in limited operating frequency range. In Proceedings of the 2016 IEEE Energy Conversion Congress and Exposition (ECCE), Milwaukee, WI, USA, 18-22 September 2016; pp. 1-6.

14. Zhang, W.; Mi, C.C. Compensation topologies of high-power wireless power transfer systems. IEEE Trans. Veh. Technol. 2016, 65, 4768-4778. [CrossRef]

15. Zhang, W.; Wong, S.C.; Tse, C.K.; Chen, Q. Design for efficiency optimization and voltage controllability of series-series compensated inductive power transfer systems. IEEE Trans. Power Electron. 2014, 29, 191-200. [CrossRef]

16. Wang, C.W.; Stielau, O.H.; Covic, G.A. Design considerations for a contactless electric vehicle battery. IEEE Trans. Power Electron. 2005, 52, 1308-1314. [CrossRef]

17. Auvigne, C.; Germano, P.; Ladas, D.; Perriard, Y. A dual-topology ICPT applied to an electric vehicle battery charger. In Proceedings of the International Conference on Electrical Machines, Marseille, France, 2-5 September 2012; pp. $2287-2292$.

18. Qu, X.; Han, H.; Wong, S.C.; Tse, C.K.; Chen, W. Hybrid WPT topologies with constant current or constant voltage output for battery charging applications. IEEE Trans. Power Electron. 2015, 30, 6329-6337. [CrossRef]

19. Madawala, U.K.; Thrimawithana, D.J. A bidirectional inductive power interface for electric vehicles in V2G systems. IEEE Trans. Ind. Electron. 2011, 58, 4789-4796. [CrossRef]

20. Li, S.; Li, W.; Deng, J.; Nguyen, T.D.; Mi, C. A double-sided LCC compensation network and its tuning method for wireless power transfer. IEEE Trans. Veh. Technol. 2015, 64, 2261-2273. [CrossRef]

21. Feng, H.; Cai, T.; Duan, S.; Zhao, J.; Zhang, X.; Chen, C. An LCC compensated resonant converter optimized for robust reaction to large coupling variation in dynamic wireless power transfer. IEEE Trans. Ind. Electron. 2016, 63, 6591-6601. [CrossRef]

22. Kan, T.; Nguyen, T.D.; White, J.C.; Malhan, R.K.; Mi, C. A new integration method for an electric vehicle wireless charging system using LCC compensation topology: Analysis and design. IEEE Trans. Power Electron. 2017, 32, 1638-1650. [CrossRef]

23. Qu, X.; Jing, Y.; Han, H.; Wong, S.C.; Tse, C.K. Higher order compensation for inductive-power-transfer converters with constant voltage or constant-current output combating transformer parameter constraints. IEEE Trans. Power Electron. 2017, 32, 394-405. [CrossRef]

24. Neath, M.J.; Swain, A.K.; Madawala, U.K.; Thrimawithana, D.J. An optimal PID controller for a bidirectional inductive power transfer system using multiobjective genetic algorithm. IEEE Trans. Power Electron. 2014, 29, 1523-1531. [CrossRef]

25. Kim, M.; Joo, D.M.; Lee, B.K. Design and control of inductive power transfer system for electric vehicles considering wide variation of output voltage and coupling coefficient. IEEE Trans. Power Electron. 2019, 34, 1197-1208. [CrossRef] 
26. Chen, Y.F.; Zhang, H.L.; Park, S.J.; Kim, D.H. A switching hybrid LCC-S compensation topology for constant current/voltage EV wireless charging. IEEE Access 2019, 7, 133924-133935. [CrossRef]

27. Zhang, H.L.; Chen, Y.F.; Park, S.J.; Kim, D.H. Hybrid compensation topology with single switch for battery charging of inductive power transfer systems. IEEE Access 2019, 7, 171095-171104. [CrossRef]

28. Cai, C.S.; Wang, J.; Fang, Z.; Zhang, P.; Hu, M.; Zhang, J.; Li, L.; Lin, Z. Design and optimization of load-independent magnetic resonant wireless charging system for electric vehicles. IEEE Access 2018, 6, 17264-17274. [CrossRef]

29. Wang, Y.; Yao, Y.; Liu, X.; Xu, D.; Cai, L. An LC/S compensation topology and coil design technique for wireless power transfer. IEEE Trans. Power Electron. 2018, 33, 2007-2025. [CrossRef]

30. Erickson, R.W.; Maksimovic, D. Fundamentals of Power Electronics, 2nd ed.; Kluwer: Norwell, MA, USA, 2001. 